\title{
Encapsulation of Oxidizers: Efficient Method by Spout-fluid Bed
}

\author{
Jessica de Oliveira Silva1, Josiane Ribeiro Campos Silva ${ }^{1}$, Lucas Barros de Oliveira ${ }^{1}$, Kamila Pereira \\ Cardoso², Marcio Yuji Nagamachi², Luiz Fernando de Araujo Ferrão1,*
}

Silva JO (D) https: / / orcid.org/0000-0001-5086-637X

Silva JRC (D) https://orcid.org/0000-0002-9558-8665

Oliveira LB (D) https://orcid.org/0000-0002-9350-0690

Cardoso KP (D) https://orcid.org/0000-0001-5308-0188

Nagamachi MY D https: / / orcid.org/0000-0001-7617-8647

Ferrão LFA (D) https://orcid.org/0000-0003-1294-8707
How to cite

Silva JO; Silva JRC; Oliveira LB; Cardoso KP; Nagamachi MY; Ferrão LFA (2019). Encapsulation of Oxidizers: Efficient Methos by Spout-fluid Bed. J Aerosp Technol Manag, 11, Special Edition: 23-26. https://doi.org/10.5028/jatm. etmq.66

\begin{abstract}
In composite solid propellants, the oxidizer in the form of particles is embedded in a polymeric matrix. In general, these oxidizers consist in inorganic salts that are hygroscopic, chemically incompatible or sensitive to friction or impact, so that microencapsulation can be applied as a mean to provide a protective coating layer. This work aims to assess the effectiveness of the spout-fluid bed method to perform microencapsulation of ammonium perchlorate particles with acrylic-based resin. The formed coating integrity was assessed by an optical stereomicroscope for samples with one, two and four layers of coating before and after dissolving the cores in water. The parameters utilized in this method provided a complete and individualized encapsulation with sufficient integrity. Therefore, the spout-fluid bed method proved to be effective, particularly with the application of multiple layers.
\end{abstract}

KEYWORDS: Ammonium perchlorates; Solid rocket propellants; Composite propellants; Encapsulating.

\section{INTRODUCTION}

Microencapsulation can be applied to coat particles for different purposes such as isolation, control of core release, safe handling, masking of a specific characteristic or to protect it from the external environment (Jyothi et al. 2010; Nagamachi et al. 2009). On the other hand, oxidizers particles in composite propellants are embedded in a polymeric binder that also serves as a fuel, and even though many inorganic compounds are categorized as such, ammonium perchlorate (AP) is by far the most employed oxidizer in this kind of propellant. The need for microencapsulation of oxidizers usually comes from their high hygroscopicity, lack of chemical compatibility or high sensitivity to impact or friction. The coating material is usually made out of a polymeric resin whose cure or hardening advances to the extent that agglomeration is prevented, which otherwise would have a negative impact on particles packing and the maximum solid loading as a consequence. The coating material needs indeed to be chemically compatible with the oxidizer and should not impair the final propellant which must be previously verified.

The spout-fluid bed is a microencapsulation method in which a resin is previously diluted in a solvent and sprayed onto the particles such as paint. The cure or hardening gradually takes place as the solvent evaporation proceeds (Altzibar et al. 2010; Heintz et al. 2012; Guignon et al. 2002). In that process, the particles at the bottom-center of the bed are spouted upwards by warm air

\footnotetext{
1.Departamento de Ciências e Tecnologia Aeroespacial - Instituto Tecnológico de Aeronáutica - Divisão de Ciências Fundamentais - São José dos Campos/SP - Brazil 2.Departamento de Ciências e Tecnologia Aeroespacial - Instituto de Aeronáutica e Espaço - Divisão de Propulsão - São José dos Campos/SP - Brazil

*Correspondence author: ferrao@ita.br

Received: 27 Nov 2019 | Accepted: 10 Dec 2019

Note: This paper was selected from the 10 Encontro Técnico de Materiais e Química (ETMQ) ocurred in 27-29 november of 2019 and organized by Instituto de Pesquisas da Marinha (IPqM) in Rio de Janeiro/RJ, Brazil
} 
pumped from the bottom and then fall sideward forming a fountain. The particles then move down through the fluid-bed and back to the bottom-center due to the conical base shape. The cycle repeats and creates an internal circulating movement. The resin diluted in a solvent is sprayed on the top of the fountain, scattering droplets over the surface of the emerging particles where it cures or hardens. In this work, microencapsulation of AP particles with the spout-fluid bed method was assessed in order to determine its effectiveness to coat AP particles. The integrity of the capsules was examined by means of an optical stereomicroscope by comparing micrographs before and after immersion of the microencapsulated particles in water.

\section{MATERIALS AND METHODS}

Materials: ammonium perchlorate (mean diameter $=420 \mu \mathrm{m}$ ) of AEQ as a core material; aqueous solution containing $30 \%$ R180W acrylic resin (Redelease), $0.6 \%$ red dye and $69.4 \%$ water in mass as spraying material.

Methods: microencapsulation of AP was performed in a VFC-LAB Micro of Freund-Vector. Initially, $30.0 \mathrm{~g}$ of AP was put inside the conical vessel and let warm air $\left(\sim 45^{\circ} \mathrm{C}\right)$ spout upwards through the particles bed at the rate of $130 \mathrm{~L} \cdot \mathrm{min}^{-1}$, then $1.5 \mathrm{~mL}$ of spraying material was applied over the top of the formed fountain. The coated particles were left circulating for $10 \mathrm{~min}$ in order to make sure that the whole solvent was eliminated. The application was performed one, two or four times consecutively under the same conditions depending on the number of coating layers (one, two or four, respectively). Capsule integrity: Morphology and integrity of the capsules were examined by means of a Discovery V12 optical stereomicroscope of Carl-Zeiss; micrographs were taken before and after the coated AP particles were immersed in water and stirred manually (at room temperature) to accelerate the core dissolution.

\section{RESULTS AND DISCUSSION}

The samples with one, two and four coating layers are shown in Fig. 1. The uniform coloration indicates that the samples did not present agglomerates, suggesting that the parameters and conditions adopted in this process were appropriate. It is noteworthy that the color becomes darker as the number of layers increases.

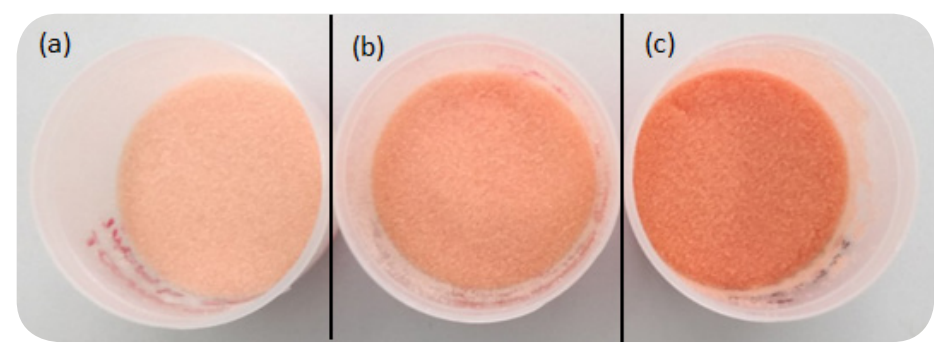

Figure 1. Samples of microencapsulated AP with acrylic-based coating: (a) one layer, (b) two layers and (c) four layers of coating.

The obtained microencapsulated AP was immersed in water in order to dissolve the core such that the capsule integrity could be better assessed, as shown in the micrographs in Figs. 2b,d. Figures 2a,c shows that the AP particles were uniformly microencapsulated, without evidence of any significant morphological changes or excessive accumulation of acrylic-based coating, which is seen in reddish color due to the presence of dye. The micrographs in Figs. 2b,d show the remaining acrylic-based coats after the AP core is completely dissolved in water. It is noteworthy that the remaining coatings in Fig. $2 \mathrm{~d}$ (corresponding to the four-layer coating) preserved their morphology and structural integrity.

On the other hand, the remaining coatings morphology in Fig. $2 \mathrm{~b}$ are not preserved, which suggests that the application of two layers is not sufficient to protect and preserve the capsules integrity. The remaining capsules in Figs. 2b,d had their reddish 
color faded, which is an indication of dye dissolution in water. The latter behavior has the potential to form emptiness or to cause flaws on the capsule that could lead to a lack of integrity, as seen in Fig. 2b:

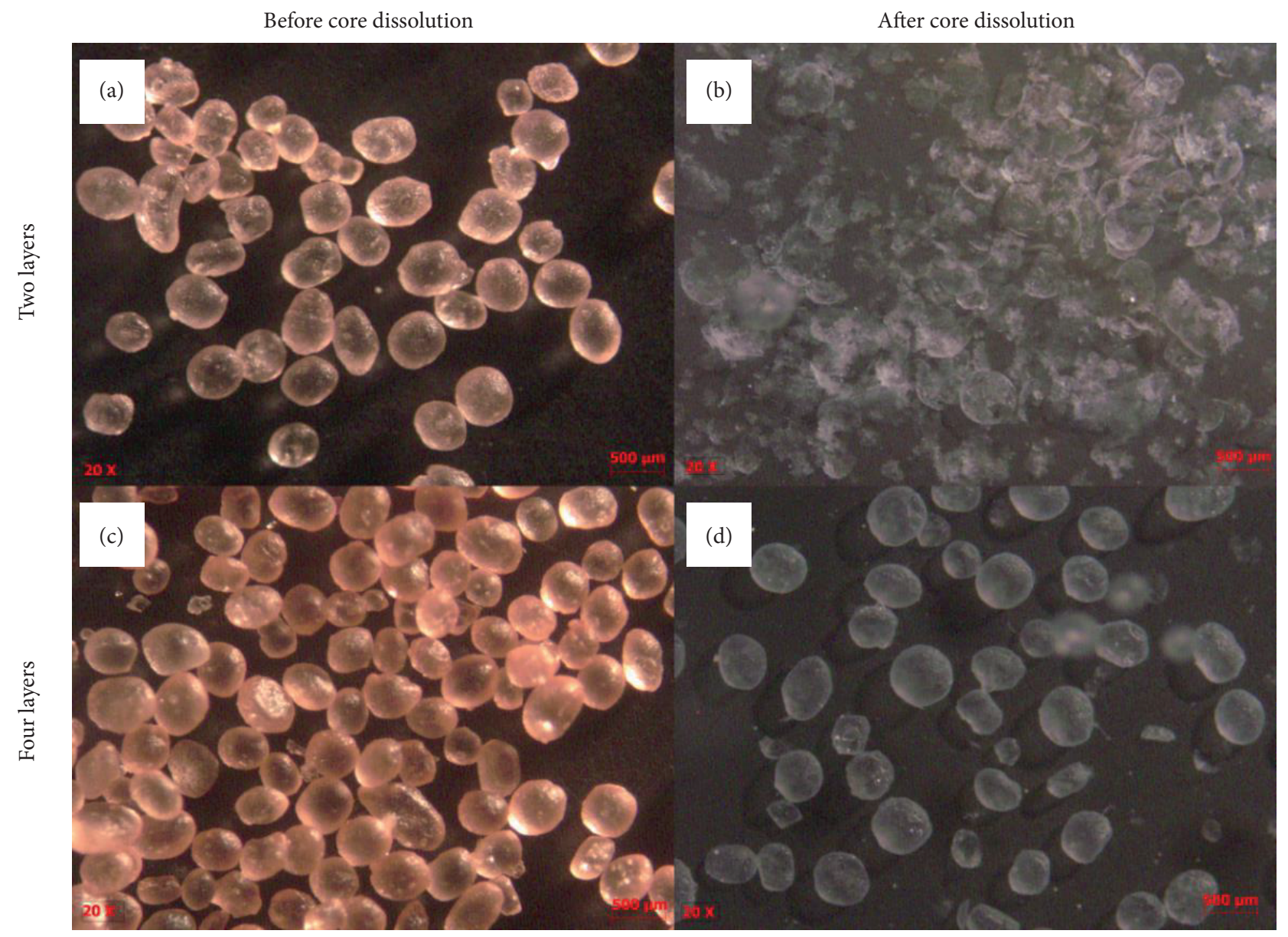

Figure 2. Microencapsulated ammonium perchlorate particles with acrylic-based coating: (a) two-layer coating before core dissolution, (b) two-layer coating after core dissolution, (c) four-layer coating before core dissolution and (d) four-layer coating after core dissolution.

\section{CONCLUSION}

This work has succeeded in assessing the spout-fluid bed microencapsulation method to apply acrylic-based coating on ammonium perchlorate particles. This method was capable to form individual and homogeneous capsules on AP particles surfaces with structural integrity, particularly, for microencapsulation performed with the application of multiple layers.

\section{ACKNOWLEDGEMENTS}

The authors acknowledge the technicians and researchers of IAE for the support and friendship. 


\section{FUNDING}

Fundação de Amparo à Pesquisa do Estado de São Paulo [http://doi.org/10.13039/501100001807]

Grants (2017/00618-5 and 2019/03729-8)

Conselho Nacional de Desenvolvimento Científico e Tecnológico [http://doi.org/10.13039/501100003593]

Grants (309051/2016-9, 157662/2018-7 and 406107/2016-5)

Coordenação de Aperfeiçoamento de Pessoal de Nível Superior [http://doi.org/10.13039/501100002322]

Grant (88887.142345/2017-00)

\section{AUTHORS' CONTRIBUTION}

Conceptualization, Nagamachi MY; Methodology, Silva JO; Oliveira LB and Nagamachi MY; Research, Silva JO, Silva JRC, Oliveira LB, Cardoso KP; Nagamachi MY and Ferrão LFA; Writing - First version, Silva JO, Cardoso KP and Ferrão LFA; Writing - Review \& Editing, Silva JO, Cardoso KP, Nagamachi MY and Ferrão LFA; Acquisition of Funding, Cardoso KP and Ferrão LFA; Resources, Nagamachi MY; Supervision, Nagamachi MY and Ferrão LFA

\section{REFERENCES}

Altzibar H, Lopez G, Olazar M, Bilbao J (2010) Study of the minimum spouting velocity in a draft tube conical spouted bed. The 13th International Conference on Fluidization - New Paradigm in Fluidization Engineering; Gyeongju, Korea.

Guignon B, Duquenoy A, Dumoulin ED (2002) Fluid bed encapsulation of particles: Principles and practice. Dry Technol 20(2):419-447. https://doi.org/10.1081/DRT-120002550

Heintz T, Herrmann M, Aniol J, Fuchs A (2012) Processing of energetic composite particles by fluidized bed technology. International Annual Conference of the Fraunhofer ICT; Pfinztal, Germany.

Jyothi NV, Prasanna PM, Sakarkar SN, Prabha KS, Ramaiah PS, Srawan GY (2010) Microencapsulation techniques, factors influencing encapsulation efficiency. J Microencapsul 27(3):187-197. https://doi.org/10.3109/02652040903131301

Nagamachi MY, Oliveira JIS, Kawamoto AM, Dutra RCL (2009) ADN - The new oxidizer around the corner for an environmentally friendly smokeless propellant. J Aerosp Technol Manag 1(2):153-160. https://doi.org/10.5028/jatm.2009.0102153160 